\title{
EXPERTS' OPINION
}

\section{Novel formulations of docetaxel, paclitaxel and doxorubicin in the management of metastatic breast cancer}

\author{
SENTHIL RAJAPPA ${ }^{1}$, ASHISH JOSHI ${ }^{2}$, DINESH C. DOVAL ${ }^{3}$, ULLAS BATRA ${ }^{3}$, REJIV RAJENDRANATH ${ }^{4}$, \\ AVINASH DEO ${ }^{5}$, GHANSHYAM BISWAS ${ }^{6}$, PEUSH BAJPAI ${ }^{7}$, T.V.S. TILAK ${ }^{8}$, SRIRAM KANE $^{9}$, KISHORE KUMAR $^{8}$, \\ MANISH KUMAR $^{10}$, AVINASH D. TALELE ${ }^{11}$, PRAKASH DEVDE ${ }^{12}$, ASHUTOSH GUPTA ${ }^{13}$, NISARG JOSHI ${ }^{14}$, \\ JAYKUMAR SEJPAL ${ }^{14}$, DEEPAK BUNGER ${ }^{14}$ and MUJTABA KHAN ${ }^{14}$ \\ ${ }^{1}$ Department of Medical Oncology, Basavatarakam Indo American Cancer Hospital and Research Institute, Hyderabad, \\ Telangana 500034; ${ }^{2}$ Nanavati Hospital, Mumbai, Maharashtra 400056; ${ }^{3}$ Rajiv Gandhi Cancer Institute and Research Centre, \\ Delhi 110085; ${ }^{4}$ Apollo Speciality Hospital, Chennai, Tamil Nadu 600096; ${ }^{5}$ Fortis SL Raheja Hospital, Mumbai, \\ Maharashtra 400016; ${ }^{6}$ Sparsh Hospital, Bhubaneswar, Odisha 751007; ${ }^{7}$ Max Super Speciality Hospital, New Delhi 110017; \\ ${ }^{8}$ Command Hospital, Bangalore, Karnataka 560007; ${ }^{9}$ Kane Hematology and Oncology Clinic, Nagpur, Maharashtra 440012; \\ ${ }^{10}$ Command Hospital, Lucknow, Uttar Pradesh 226002; ${ }^{11}$ CHL Hospital, Indore, Madhya Pradesh 452008; \\ ${ }^{12}$ Seth Nandlal Dhoot Hospital, Aurangabad, Maharashtra 431210; ${ }^{13}$ Government Medical College, Jammu, \\ Jammu and Kashmir 180001; ${ }^{14}$ Intas Pharmaceuticals Ltd., Ahmedabad, Gujarat 380061, India
}

Received October 31, 2017; Accepted May 24, 2018

DOI: $10.3892 / \mathrm{ol} .2018 .9057$

\begin{abstract}
The management of breast cancer with advanced disease or metastasis is a common problem in India and other countries. A panel of 13 oncology experts deliberated on the sidelines of the 35th Indian Cooperative Oncology Network Conference held in Mumbai to formulate an expert opinion recommendation on the novel drug delivery system (NDDS) formulations in the treatment of metastatic breast cancer (MBC). The survey comprised of 39 questions related to limitations of conventional formulations and therapeutic positioning of NDDS formulations of docetaxel, paclitaxel and doxorubicin in the management of MBC. The experts used data from published literature and their practical experience to provide expert opinion and recommendations for use by the community oncologists. The experts opined that the newer NDDS formulations should provide a significant efficacy advantage in terms of overall survival and progression-free survival, or demonstrate better tolerability when compared
\end{abstract}

Correspondence to: Dr Senthil Rajappa, Department of Medical Oncology, Basavatarakam Indo American Cancer Hospital and Research Institute, Road No 10, Banjara Hills, Hyderabad, Telangana 500034, India

E-mail: senthilrajappa@gmail.com

Key words: experts' opinion, novel drug delivery system, metastatic breast cancer, doceaqualip, pacliaqualip, pegylated liposomal doxorubicin with conventional formulations. The newer NDDS formulations of taxanes should be considered in special circumstances such as diabetes, in patients who have had hypersensitivity reactions and in cases where steroids need to be avoided. The novel formulations of doxorubicin should be used in the elderly and in patients with borderline cardiac function.

\section{Introduction}

Breast cancer is the second most common cancer globally, and the most common cancer in women, with an estimated diagnosis of 1.67 million new cases and 522,000 deaths in 2012 (1). It has an age adjusted incidence of 144,937 cases (27\%), a mortality rate of $21.5 \%$ and a 5-year prevalence rate of $35.3 \%$, which is the highest amongst all cancer types among women in India (1). Breast cancer accounts for $25-32 \%$ of all female cancers in India (2), and is found more in the urban areas (3). The diagnosis of breast cancer in India is generally made at a relatively advanced stage (4). Metastatic breast cancer (MBC) has a median survival of $\sim 2-3$ years with rare long-term survivors (5-year survival rates vary from 5 to $10 \%)(5)$.

Taxanes (docetaxel, paclitaxel) and anthracyclines (doxorubicin) are the most active and common chemotherapeutic agents used in the management of MBC with an objective response yield of $20-80 \%$ as single agents (6-8). Although these chemotherapeutic agents have led to improvements in survival, they are associated with a few challenges regarding their safety (9), for example, acute hypersensitivity reactions (10), fluid retention (11), and peripheral neuropathy (12) with docetaxel; severe anaphylactoid hypersensitivity reactions, hyperlipidemia, abnormal lipoprotein patterns, aggregation of 
erythrocytes, peripheral neuropathy (13) and altered pharmacokinetic profile with paclitaxel (14); cardiotoxicity, narrow therapeutic index myelosuppression, alopecia, severe acute nausea and vomiting, and mucositis with doxorubicin (15).

Consequently, to overcome the undesirable toxicities of these conventional formulations, several novel drug delivery approaches including liposomes, PEGylated nanoliposomes, nanostructured lipid carriers (NLCs), poly (lactide-co-glycolide) (PLGA) nanospheres, chitosan nanoparticles, conjugates, oral solid dispersion and $\beta$-cyclodextrin complexes have been investigated (16). The novel drug delivery systems (NDDS) provide remarkable advantages in terms of enhancement of solubility, bioavailability, stability, tissue macrophages distribution, pharmacological activity, sustained delivery, protection from toxicity, and physical and chemical degradation (17).

To facilitate and draw the attention of the oncologist community towards the optimal use of NDDS formulations in the management of MBC, a meeting of a panel of oncology experts from India was held to opine at the 35 th ICON conference in Mumbai, India, on 10th September 2016. The objectives of the meeting were to examine the limitations of conventional formulations and advantages of novel drug formulations, and provide expert opinion on the use of novel drug formulations of docetaxel, paclitaxel, and doxorubicin in the management of MBC based on published evidence and own experience.

\section{Methodology}

The expert opinion meeting at the 35 th Indian Cooperative Oncology Network Conference, 2016 was moderated by Dr Senthil Rajappa and Dr Ashish Joshi. Sets of questionnaires on the positioning of NDDS formulations of docetaxel, paclitaxel and doxorubicin in the management of MBC were prepared based on the available published data and suggestions from experts in the field. Presentations were made to discuss the limitations of conventional formulations, and the therapeutic positioning of novel formulations, followed by the circulation of questionnaires to all 13 panel members for discussion and voting to elicit their expert opinion, during the meeting. Drs Nisarg Joshi, Jaykumar Sejpal, Deepak Bunger and Mujtaba Khan (Intas Pharmaceuticals, Ltd., Ahmedabad, India) were not a part of voting. The details of the questions asked and the experts' opinions with available evidence are summarized below for docetaxel, paclitaxel and doxorubicin.

\section{Docetaxel}

Dosing schedule. Conventional docetaxel is approved for the treatment of MBC as a single agent at a dose of $60-100 \mathrm{mg} / \mathrm{m}^{2}$ administered intravenously every 3 weeks (18). In a phase III study, as a second-line treatment for advanced breast cancer, increasing the dose of docetaxel across the dose range of $60-100 \mathrm{mg} / \mathrm{m}^{2}$ every 3 weeks was associated with a promising response and an improved time to disease progression (TTP) (19). Higher doses of docetaxel can be given to those patients initially started at $60 \mathrm{mg} / \mathrm{m}^{2}$ dose in the absence of adverse effects (18).

The National Comprehensive Cancer Network (NCCN) guidelines recommend docetaxel $\left(60-100 \mathrm{mg} / \mathrm{m}^{2}\right.$ every
3 weeks) as a single agent or in combination (at $75 \mathrm{mg} / \mathrm{m}^{2}$ ) with capecitabine for the treatment of recurrent or MBC (20). Docetaxel $\left(75 \mathrm{mg} / \mathrm{m}^{2}\right)$ in combination with capecitabine (950 mg/m² orally twice daily) given 3-weekly was effective in prolonging the TTP with considerable safety profile, and was recommended as a front-line treatment of advanced breast cancer (21).

Docetaxel in combination with trastuzumab \pm pertuzumab is recommended as the preferred first line agent for human epidermal growth factor receptor 2 (HER2) positive MBC. In HER2 positive MBC patients, 3-weekly docetaxel $\left(100 \mathrm{mg} / \mathrm{m}^{2}\right)$ in combination with trastuzumab $(4 \mathrm{mg} / \mathrm{kg}$ loading dose followed by $2 \mathrm{mg} / \mathrm{kg}$ weekly) showed a high overall response rate (ORR), overall survival (OS), response duration, time to progression, and time to treatment failure (TTF); toxicity was little more than docetaxel single agent (22). Similarly, weekly docetaxel $\left(35 \mathrm{mg} / \mathrm{m}^{2}\right)$ in combination with trastuzumab ( $4 \mathrm{mg} / \mathrm{kg}$ loading dose followed by $2 \mathrm{mg} / \mathrm{kg}$ weekly) showed a high ORR $(67 \%)$ in patients with HER2 positive MBC (23). Furthermore, 3-weekly docetaxel $\left(75-100 \mathrm{mg} / \mathrm{m}^{2}\right)$ in combination with pertuzumab $(840 \mathrm{mg}$ day 1 followed by $420 \mathrm{mg})+$ trastuzumab $(8 \mathrm{mg} / \mathrm{kg}$ loading dose followed by $6 \mathrm{mg} / \mathrm{kg}$ ), when used as first-line treatment for HER2 positive disease, significantly prolonged progression-free survival (PFS) as compared with docetaxel + trastuzumab; no increase in cardiac toxicity was observed (24).

Docetaxel (100 mg/m 3 weekly) in combination with bevacizumab (15 mg/kg 3 weekly) showed improved median PFS in HER2 negative MBC patients in a phase III study (25). A retrospective analysis of phase III clinical data demonstrated the effectiveness of docetaxel alone or in combination with capecitabine in patients with ER positive or negative MBC (26). Furthermore, docetaxel in combination with cisplatin was effective (PFS: 10.4 months) as the first-line treatment of metastatic triple-negative breast cancer (mTNBC) (27).

Overall, the expert panel members (100\%) opined that the most preferred dose of docetaxel as a single agent in $\mathrm{MBC}$ is $75 \mathrm{mg} / \mathrm{m}^{2}$ (Table I).

Challenges with conventional docetaxel formulations. The most common challenges with docetaxel treatment in the clinical setting include the requirement of corticosteroid premedication as severe hypersensitivity reactions have been reported with some cases of fatal anaphylaxis, and fluid retention (18), which are attributed to the carrier, polysorbate 80 , used in the formulation. The expert panel members opined that neutropenia, corticosteroid premedication and edema are the most common challenges, which may limit the use of docetaxel. Even if these toxicities were manageable, all the members $(100 \%)$ concurred that they would prefer not to use $100 \mathrm{mg} / \mathrm{m}^{2}$ dose for the treatment of MBC (Table I).

Use of granulocyte colony stimulating factor (GCSF). Real-world clinical data indicates that patients treated with chemotherapy often require GCSF support to address the risk of neutropenia. The expert panel members (100\%) agreed that they use primary prophylaxis with filgrastim, a GCSF, irrespective of the dose of docetaxel (Table I). In a retrospective analysis conducted by Ashraf et al, in adult patients with solid tumors, who received the novel formulation of docetaxel, 
Table I. Expert's opinion on use of docetaxel, paclitaxel and doxorubicin formulations in MBC.

Dosing schedule of docetaxel

Experts' opinion (\% of responding experts)

Q 1. What is your preferred dose of docetaxel as a single agent in MBC?
a) $60 \mathrm{mg} / \mathrm{m}^{2}$
b) $75 \mathrm{mg} / \mathrm{m}^{2}$
c) $100 \mathrm{mg} / \mathrm{m}^{2}$

$75 \mathrm{mg} / \mathrm{m}^{2}(100)$

Challenges with conventional docetaxel formulations

Q 2. In your clinical practice, which are the most common limitations of conventional docetaxel that limit its use?

Q 3. If toxicity was manageable, would you use $100 \mathrm{mg} / \mathrm{m}^{2}$ dose in MBC?

Neutropenia, use of steroids as premedication, and edema

a) Yes

No (100)

Use of granulocyte colony stimulating factor

Q 4. Do you use primary prophylaxis with GCSF irrespective of the dose?

Yes (100)
a) Yes
b) No

Duration of taxane therapy

Q 5. From toxicity point of view, which is the preferred taxane and schedule?
a) Paclitaxel 3 weekly
b) Paclitaxel weekly
c) Docetaxel 3 weekly
d) Docetaxel weekly

Q 6. What is your taxane of choice in patients who can not come to the

Paclitaxel 3 weekly (100) hospital weekly for logistic reasons?
a) Paclitaxel 3 weekly
b) Paclitaxel weekly
c) Docetaxel 3 weekly
d) Docetaxel weekly

Corticosteroid premedication

Q 7. Are we strict with steroid prophylaxis?
a) Yes
b) No

Q 8. Is use of steroid premedication a major worry with respect to infections

Yes (100) and hyperglycemia?
a) Yes
b) No

Q 9. Which of following is the most important reason to choose the

No need of corticosteroid novel formulation of docetaxel over the conventional one?
a) Efficacy
b) Toxicity
c) No need of corticosteroid premedication
d) Better QOL for patients

Q 10. Do you feel that using a novel formulation of docetaxel would add premedication (100) value to current management of breast cancer in a metastatic setting?
a) Yes
b) $\mathrm{No}$ 
Table I. Continued.

Novel formulations of docetaxel

Q 11. Is the data of NDLS convincing with regards to?
a) Efficacy
b) Safety

Q 12. In what fraction of patients who are eligible for docetaxel, you use a novel formulation in your clinical practice currently?

Q 13. In your opinion, using a novel formulation of docetaxel would add value in which setting of breast cancer?
a) Metastatic setting
b) Neoadjuvant setting
c) Adjuvant setting

Q 14. If cost of novel formulations is not a constraint, I will prescribe novel formulation of docetaxel for:
a) All my patients who are candidates for docetaxel
b) Some of my patients in special circumstances
c) None of my patients

Q 15. In which sub-group of patients would you strongly prefer novel formulation of docetaxel over conventional formulation?

\section{Safety (85)}

Not sure (15)

More data on efficacy is needed (100)

In $10-30 \%$ of patients (62)

In $<10 \%$ of patients (15)

No response (23)

Metastatic setting (85)

Not sure (15)

Some of my patients in

special circumstances (100)

Diabetics and patients in whom to avoid steroids in a metastatic setting (100)

Dosing schedule of paclitaxel

Q 16. What is your preferred regimen for paclitaxel in the management

Weekly (80 to $\left.100 \mathrm{mg} / \mathrm{m}^{2}\right)(100)$ of metastatic breast cancer?
a) Weekly (80 to $100 \mathrm{mg} / \mathrm{m}^{2}$ )
b) Every three weeks $\left(175 \mathrm{mg} / \mathrm{m}^{2}\right)$
c) Other specify

Challenges with conventional paclitaxel formulations

Q 17. Which are the most troublesome problems with conventional paclitaxel?

Hypersensitivity reactions, neuropathy, need for special IV infusion set, and longer infusion time (100)

Novel formulations of paclitaxel

Q 18. What is the most feasible dose of weekly nab-paclitaxel in $100 \mathrm{mg} / \mathrm{m}^{2}(100)$ $\mathrm{MBC}$ in our country?
a) $100 \mathrm{mg} / \mathrm{m}^{2}$
b) $125 \mathrm{mg} / \mathrm{m}^{2}$
c) $150 \mathrm{mg} / \mathrm{m}^{2}$
d) Other specify

Q 19. Do you feel that prescribing novel formulation of paclitaxel would Yes (100) add value to the current management of metastatic breast cancer?
a) Yes
b) $\mathrm{No}$
c) Not sure

Q 20. Which of the following is the greatest advantage offered by a Avoiding steroid premedication (100) cremaphor free paclitaxel formulation?
a) Efficacy
b) Safety
c) Avoiding steroid premedication
d) Short infusion time 
Table I. Continued.

e) Better QOL for patients

f) Other, specify

Q 21. With lower doses of dexamethasone $4 \mathrm{mg}$ being adequate for prophylaxis, would you still want to avoid conventional paclitaxel?
a) Yes
b) No
c) Not sure

Q 22. In your opinion, using novel formulation of paclitaxel adds value in which setting for breast cancer?
a) Neoadjuvant setting
b) Adjuvant setting
c) Metastatic setting

Q 23. What fraction of patients who are eligible for paclitaxel, do you use novel formulation in your clinical practice?

Q 24. If cost of novel formulation is not a constraint, I will prescribe novel formulation of paclitaxel for ...

a) All of my patients who are candidates for paclitaxel

b) Some of my patients in special circumstances

c) None of my patients

Q 25. In which sub-group of patients (any specific clinical settings or sub types of breast cancer) do you strongly prefer novel formulation of paclitaxel over conventional formulation?
Yes (46)

No (54)

Metastatic setting (100)

$<10 \%$ of patients $(92)$;

$10-20 \%$ (8)

Some of my patients in special circumstances (100)

Diabetics, patients who had

hypersensitivity reactions to convent ional paclitaxel formulation and in whom steroid needs to be avoided (100)

Pegylated liposomal doxorubicin

Q 26. What is the most common dose of PLD in clinical practice?
a) $30 \mathrm{mg} / \mathrm{m}^{2}$
b) $40 \mathrm{mg} / \mathrm{m}^{2}$
c) $50 \mathrm{mg} / \mathrm{m}^{2}$

$40-50 \mathrm{mg} / \mathrm{m}^{2}(100)$

PLD vs. conventional doxorubicin

Q 27. In which setting do you prefer PLD over conventional doxorubicin?
a) Adjuvant
b) Neoadjuvant
c) Metastatic
d) All
e) None

Q 28. Do you think that PLD is less cardiotoxic?

Yes (77)

a) Yes

Not sure (23)

b) No

c) Not sure

Q 29. Do you feel that there is enough evidence to prove that PLD is

Not sure (100) more effective than conventional doxorubicin in MBC?

Metastatic (100)
a) Yes
b) $\mathrm{No}$
c) Not sure

Cumulative dose of PLD

Q 30. Do you feel that there should be any limit for the cumulative dose of PLD?

Not sure (100)
a) Yes
b) No
c) Not sure 
Table I. Continued.

Palmar-plantar erythrodysesthesia (PPE) with PLD

Q 31. Do you feel that PPE is more common with PLD than with conventional doxorubicin?
a) Yes
b) No
c) Not sure

Yes (73)

Not sure (27)

Manageable (100)

Q 32. What do you feel about PPE?

a) Troublesome

b) Manageable

Q 33. Which are the other toxicities of concern with PLD?

Myelotoxicity, neutropenia, hypersensitivity and infusion site reactions (100)

PLD in anthracycline rechallenge

Q 34. In patients exposed to doxorubicin in the adjuvant setting, how frequently do you need to rechallenge patients with PLD?

Rare (100)
a) Rare
b) Frequent
c) Not sure

Q 35. Do you feel that it is safe to rechallenge patients with PLD in MBC setting Yes (46) (those exposed to doxorubicin in adjuvant setting)?

No (23)
a) Yes
b) $\mathrm{No}$
c) Not sure

PLD in the elderly with MBC

Q 36. Would PLD be preferred in elderly and in those with borderline cardiac

Yes (100) function, in whom doxorubicin is planned to be administered?
a) Yes
b) No
c) Not sure

Combination of PLD with trastuzumab

Q 37. Can trastuzumab be used concurrently with PLD?
a) Yes
b) $\mathrm{No}$
c) Not sure

No (77)

Not sure (23)

\section{Generic PLD formulations}

Q 38. Is the data available on generic PLD satisfactory?
a) Yes
b) No
c) Not sure

Q 39. Any preferences among generic PLD?
a) None
b) I do not use PLD
c) I prefer one over the other. Reason?

Not sure (100)

None (100)

MBC, metastatic breast cancer; NDLS, nanosomal docetaxel lipid suspension; GCSF, granulocyte colony stimulating factor; PLD, pegylated-liposome encapsulated doxorubicin; PPE, palmar-plantar erythrodysesthesia. 
Table II. Adverse events profile: NDLS vs. taxotere ${ }^{\circledR}$

\begin{tabular}{lcc}
\hline $\begin{array}{l}\text { Adverse events } \\
\text { (all grades) }\end{array}$ & $\begin{array}{c}\text { NDLS, } \\
75 \mathrm{mg} / \mathrm{m}^{2}(\%)\end{array}$ & $\begin{array}{c}\text { Taxotere }^{\circledR} \\
75 \mathrm{mg} / \mathrm{m}^{2}(\%)\end{array}$ \\
\hline Vomiting & 10 & 22 \\
Alopecia & 35 & 26 \\
Diarrhea & 29 & 22 \\
Neutropenia & 77.5 & 52.2 \\
\hline
\end{tabular}

NDLS, nanosomal docetaxel lipid suspension.

nanosomal docetaxel lipid suspension (NDLS) as monotherapy $\left(75-100 \mathrm{mg} / \mathrm{m}^{2}\right)$ did not require GCSF support, whereas patients who received dual/triplet chemotherapy (NDLS + platinum derivative/5-fluorouracil/gemcitabine/capecitabine) required 2-3 doses of GCSF to normalize counts (28). Though the above data indicate that lower doses of GCSF are required with NDLS, the expert panel members opined that they would prefer to use GCSF with all docetaxel formulations.

Duration of taxane therapy. Weekly schedule of docetaxel-based chemotherapy was found inferior to 3-weekly ones in terms of response rate (29), and quality of life in locally advanced or MBC (30). In a combined HER2 positive or negative patient pool, weekly paclitaxel was found to be more effective [(42) vs. $29 \%$; unadjusted odds ratio $(\mathrm{OR})=1.75$; $\mathrm{P}=0.0004]$ and less toxic (more common Grade 3 neuropathy with weekly dosing: $24 \%$ vs. $12 \% ; \mathrm{P}=0.0003$ ) when compared with a 3-weekly administration in patients with MBC (31). Higher ORR (72\% vs. 26\%; $\mathrm{P}=0.01$ ) was observed with weekly paclitaxel $80 \mathrm{mg} / \mathrm{m}^{2}$ compared with 3-weekly docetaxel $75 \mathrm{mg} / \mathrm{m}^{2}$ regimen, both given in combination with oral capecitabine $1,000 \mathrm{mg} / \mathrm{m}^{2}$ twice daily for 2 weeks followed by a 1-week break (32). The expert panel members (100\%) agreed that from a toxicity point of view, the most preferred taxane and schedule is the paclitaxel weekly regimen. For patients who can not visit the hospital every week for logistic reasons, paclitaxel 3-weekly regimen is preferred by the expert panel members $(100 \%)$ (Table I).

Corticosteroid premedication. The expert panel members $(100 \%)$ were strict with corticosteroid prophylaxis in breast cancer, and opined that corticosteroid premedication is a major worry with respect to infections and hyperglycemia. All the experts agreed that avoiding corticosteroid premedication is the most important reason for choosing a novel formulation of docetaxel over the conventional formulation (Table I).

Novel formulations of docetaxel. Several novel formulations such as taxane analogues and prodrugs, docetaxel-encapsulated nanoparticle-aptamer bioconjugates albumin nanoparticles, polyglutamates, emulsions, liposomes, docetaxel fibrinogen-coated olive oil droplets and submicronic dispersion have been developed to avoid the toxicities of the carrier used in docetaxel formulations (33). Nano Aqualip Technology, that has nano-carriers in suspension form, composed of lipids Generally Regarded As Safe (GRAS) by the US Food and Drug Administration (FDA), was used to develop NDLS (Doceaqualip), for improved stability and pharmacokinetics, and protection of docetaxel from the surrounding tissue environment. The nanonized particles of NDLS $(\sim 100 \mathrm{~nm})$ penetrate into tumor tissues through leaky vasculature without being attacked by the body's immune system. Doceaqualip was primarily developed to avoid toxicities associated with polysorbate 80 and ethanol and thus, to avoid the premedications $(34,35)$.

NDLS vs. conventional docetaxel. Therapeutic efficacy of NDLS was compared with Taxotere ${ }^{\circledR}$, both administered as I.V. infusions over $1 \mathrm{~h}$ at a dose of $75 \mathrm{mg} / \mathrm{m}^{2}$ in 72 locally advanced or MBC patients who had previously failed chemotherapy (35). The ORR for NDLS was 35.5\% compared with $26.3 \%$ for Taxotere ${ }^{\circledR}$. Patients in the NDLS group were not premedicated with corticosteroids but the safety results of NDLS were comparable with Taxotere ${ }^{\circledR}$ and most of the adverse events (AEs) resolved without any sequelae. Serious allergic reactions like bronchospasm or swelling of face were not observed with NDLS (Table II). The incidence of neutropenia was higher with NDLS $75 \mathrm{mg} / \mathrm{m}^{2}$ treatment compared with Taxotere ${ }^{\circledR} 75 \mathrm{mg} / \mathrm{m}^{2}(77.5 \%$ vs. $52.2 \%)$ in this study; however, previous studies have observed $96.7 \%$ incidence of neutropenia with Taxotere ${ }^{\circledR} 75 \mathrm{mg} / \mathrm{m}^{2}$ dose (19). Febrile neutropenia was consistent with that reported for Taxotere $^{\circledR}$.

The expert panel members (100\%) opined that using a novel formulation of docetaxel would add value to the current management of breast cancer in a metastatic setting. Majority $(85 \%)$ of the expert panel members agreed that the data of NDLS seems convincing with respect to safety; however, all the expert members agreed that there is a need to generate more data on the efficacy of NDLS. Currently, majority (62\%) of the expert panel members use a novel formulation of docetaxel in their clinical practice in $10-30 \%$ of patients who are eligible for docetaxel treatment. Majority of them (85\%) agreed that using a novel formulation of docetaxel would add value in the metastatic setting of breast cancer. If the cost of novel formulations is not a constraint, all of them $(100 \%)$ would prescribe NDLS in diabetics and in those patients where steroids need to be avoided in a metastatic setting (Table I).

Overall, docetaxel has been shown to be effective in the treatment of recurrent or MBC including the subgroups of HER2 positive/negative patients and mTNBC. NDLS is the only NDDS of docetaxel approved and available in India, and the subgroup analysis data on the same is not available in published literature.

\section{Paclitaxel}

Paclitaxel is a preferred single chemotherapeutic agent for recurrent or MBC according to NCCN guidelines 2017 (20). The recommended dose of paclitaxel is $175 \mathrm{mg} / \mathrm{m}^{2}$ administered over a period of $3 \mathrm{~h}$, every 3 weeks or $80 \mathrm{mg} / \mathrm{m}^{2}$ every week $(37,38)$. Paclitaxel in combination with trastuzumab \pm pertuzumab are preferred first-line agents for HER2 positive disease as per the NCCN guidelines. Paclitaxel $175 \mathrm{mg} / \mathrm{m}^{2}$ every 3 weeks in combination with trastuzumab ( $4 \mathrm{mg} / \mathrm{kg}$ followed by $2 \mathrm{mg} / \mathrm{kg}$ weekly) showed 
improved TTP and median survival vs. paclitaxel alone in HER 2 overexpressor patients (39). In combination with trastuzumab (4 mg/kg followed by $2 \mathrm{mg} / \mathrm{kg}$ weekly) and pertuzumab ( $840 \mathrm{mg}$ followed by $420 \mathrm{mg} 3$ times weekly), paclitaxel $\left(80 \mathrm{mg} / \mathrm{m}^{2}\right.$ weekly) showed an improved PFS in HER 2 positive patients (40). Paclitaxel as first line therapy in HER2 negative MBC patients showed a median survival time of 19.8 months in a large-scale, real-life setting study (41). Furthermore, paclitaxel $\left(175 \mathrm{mg} / \mathrm{m}^{2}\right)$ in combination with gemcitabine $\left(1,250 \mathrm{mg} / \mathrm{m}^{2}\right)$ showed promising PFS of 6.47 months as the first line treatment of mTNBC in a phase III study (42). Another study showed the effectiveness of weekly paclitaxel in combination with carboplatin and bevacizumab in the treatment of mTNBC (43).

Dosing schedule. Weekly scheduling is more preferred based on the results of a meta-analysis, which showed that compared with every three-weekly treatment, weekly administration of paclitaxel resulted in an improvement in OS [hazard ratio (HR) 0.78 ; 95\% confidence interval (CI), 0.67-0.89] (44). All the expert panel members agreed that the most preferred dose of paclitaxel as a single agent in $\mathrm{MBC}$ is $80-100 \mathrm{mg} / \mathrm{m}^{2}$ weekly (Table I).

Challenges with conventional paclitaxel formulations. The conventional paclitaxel formulation possesses a few challenges regarding its safety profile with reports of severe anaphylactoid hypersensitivity reactions, hyperlipidemia, abnormal lipoprotein patterns, aggregation of erythrocytes, peripheral neuropathy (13), leaching of plasticizers from PVC bags (45), and altered pharmacokinetic profile with non-linear increase in plasma paclitaxel concentrations due to cremophor EL (CrEL) micelle encapsulation of the drug, and thereby reducing its absorption in the first hour after administration (14), and also requires corticosteroid premedication. The expert panel members opined that the most common limitations of conventional paclitaxel, which may limit its use in clinical practice, are neuropathy, hypersensitivity, need for special intravenous infusion set and a longer infusion time (Table I).

Novel formulations of paclitaxel. Novel formulations of paclitaxel were developed to eliminate CrEL from the conventional paclitaxel $\left(\operatorname{Taxol}^{\circledR}\right)$, and thus reduce the toxicities associated with it.

Nab-paclitaxel. A novel formulation of paclitaxel used in the treatment of MBC, nanoparticle albumin-bound paclitaxel or nab-paclitaxel, uses albumin as a carrier to facilitate targeted delivery to tumors with a lower distribution in healthy tissues, thus resulting in a higher uptake in tumors with improved clinical efficacy (46).

Albumin-bound paclitaxel [260 mg/m² 3 weekly (47) or $100 \mathrm{mg} / \mathrm{m}^{2}$ or $125 \mathrm{mg} / \mathrm{m}^{2}$ weekly (48)] is a recommended single agent for the treatment of recurrent or $\mathrm{MBC}$ as per the NCCN guidelines. In a phase III trial in patients with MBC receiving 3-weekly nab-paclitaxel $260 \mathrm{mg} / \mathrm{m}^{2}$ vs. Taxol $175 \mathrm{mg} / \mathrm{m}^{2}$, nab-paclitaxel demonstrated a significantly higher ORR (33\% vs. $19 \%$; P<0.001) and median TTP $(23 \%$ vs 19.6 weeks; $\mathrm{P}=0.006$ ) than Taxol $175 \mathrm{mg} / \mathrm{m}^{2} 3$-weekly. Overall, nab-paclitaxel showed a greater efficacy and a favorable safety profile compared with Taxol (47). In a randomized, multicenter, phase II study in patients $(n=302)$ with $\mathrm{MBC}$, weekly nab-paclitaxel at doses of 150 and $100 \mathrm{mg} / \mathrm{m}^{2}$ demonstrated a higher ORR than docetaxel (45\% vs. 35\%) (33). Nab-paclitaxel demonstrated a similar antitumor activity at weekly doses of $100 \mathrm{mg} / \mathrm{m}^{2}$ ( $\left.\mathrm{n}=106\right)$ compared with weekly $125 \mathrm{mg} / \mathrm{m}^{2}(\mathrm{n}=75)$ in patients with MBC that had progressed with previous taxane therapy (49). The expert panel members (100\%) opined that the preferred dose of nab-paclitaxel as a single agent in $\mathrm{MBC}$ is $100 \mathrm{mg} / \mathrm{m}^{2}$ for 3 weeks with one week off (Table I).

As a first line therapy, nab-paclitaxel $\left(125 \mathrm{mg} / \mathrm{m}^{2}\right)$, in combination with bevacizumab $(10 \mathrm{mg} / \mathrm{kg})$ in 4 weekly cycle, showed promising PFS (9.4 months) and an acceptable safety profile with no unanticipated toxicities in patients with HER2 negative $\mathrm{MBC}$ in a phase II study (50). In HER2 positive MBC patients, nab-paclitaxel $\left(100 \mathrm{mg} / \mathrm{m}^{2}\right)$ showed a PFS of 16.6 months as a first line treatment in combination with carboplatin and trastuzumab (51). Another phase II study that assessed the combination of weekly nab-paclitaxel $\left(125 \mathrm{mg} / \mathrm{m}^{2}\right)$ and trastuzumab ( $4 \mathrm{mg} / \mathrm{kg}$ followed by $2 \mathrm{mg} / \mathrm{kg}$ weekly) as first-line treatment showed a PFS of 12.8 and 18.7 months and an OS of 27.3 and 36.8 months, respectively, for HER negative $(n=50)$ and positive $(n=22)$ with locally advanced or MBC (52). nab-paclitaxel in combination with bevacizumab, and carboplatin was efficacious (PFS: 9.2 months) and well-tolerated as first-line treatment for mTNBC (53).

Paclitaxel injection concentrate for nanodispersion (PICN). Paclitaxel injection concentrate for PICN, a polyoxyethylated castor oil- and albumin-free formulation of paclitaxel, administered every 3 weeks in a phase II/III trial was as effective with similar tolerability compared with nab-paclitaxel every 3 weeks in the treatment of women aged 18-70 years with MBC, without the need for corticosteroid pretreatment. The independent radiologist-assessed ORRs were 35, 49 and $43 \%$ in the PICN $260 \mathrm{mg} / \mathrm{m}^{2}$, PICN $295 \mathrm{mg} / \mathrm{m}^{2}$, and nab-paclitaxel $260 \mathrm{mg} / \mathrm{m}^{2}$ arms, respectively (54).

Nanoparticle polymer-based paclitaxel. Nanoparticle polymer-based paclitaxel (Nanoxel) $300 \mathrm{mg} / \mathrm{m}^{2}$ demonstrated a better overall response and clinical benefit compared with CrEL paclitaxel $175 \mathrm{mg} / \mathrm{m}^{2}$. Nanoxel at a dose of $220 \mathrm{mg} / \mathrm{m}^{2}$ showed a better efficacy and safety profile than conventional paclitaxel $\left(175 \mathrm{mg} / \mathrm{m}^{2}\right)$. The incidence of musculoskeletal events, gastrointestinal toxicity, and skin/subcutaneous toxicity were comparable in all the treatment arms. Overall, the nanoparticle polymer-based paclitaxel formulation was well-tolerated and could be safely administered without any premedication (55).

Nanosomal paclitaxel lipid suspension (NPLS). An open label, randomized, multiple-dose, parallel study evaluated the efficacy and safety of intravenous infusion of NPLS (Pacliaqualip) and Taxol ${ }^{\circledR}$ in $120 \mathrm{MBC}$ patients after failure of prior chemotherapy. Patients received intravenous infusion of NPLS $175 \mathrm{mg} / \mathrm{m}^{2}$ every 3 weeks ( $\mathrm{n}=48$, Arm A) or NPLS $80 \mathrm{mg} / \mathrm{m}^{2}$ every week ( $\mathrm{n}=45$, Arm B), or Taxol ${ }^{\circledR} 175 \mathrm{mg} / \mathrm{m}^{2}$ every 3 weeks $\left(n=27\right.$, Arm C). At equal doses $\left(175 \mathrm{mg} / \mathrm{m}^{2}\right)$, NPLS showed an improved efficacy as compared with Taxol $^{\circledR}$ (ORR: $36.4 \%$ for NPLS Arm A, $46.5 \%$ for NPLS 
Arm B and 20.8\% for Paclitaxel Arm C) (56). There was an increase in the incidence of neutropenia, thrombocytopenia, urinary tract infections, pyrexia, chills and other AEs with NPLS at $175 \mathrm{mg} / \mathrm{m}^{2}$, however, these resolved without any sequelae (56).

Overall, the expert panel members (100\%) opined that using a novel formulation of paclitaxel would add value to the current management of MBC. The expert panel members (100\%) consider the greatest value in the CrEL free paclitaxel formulation is avoiding steroid premedication. With a lower dose of dexamethasone ( $4 \mathrm{mg}$ ) being adequate for prophylaxis, $54 \%$ of the expert panel members would use conventional paclitaxel. The expert panel members (100\%) opined that using a novel formulation of paclitaxel adds value in the metastatic setting of breast cancer. Most (92\%) of the panel members agreed that in clinical practice, they currently use a novel formulation in $<10 \%$ of patients who are eligible for paclitaxel treatment. If the cost of NDDS is not a constraint, majority of the panel members (61\%) will prescribe the novel formulations of paclitaxel in some of their patients in special circumstances such as diabetics, patients with hypersensitivity reactions and in cases where steroids need to be avoided (Table I).

The efficacy of conventional paclitaxel or nab-paclitaxel, alone or in combination with other agents, has been demonstrated in the treatment of subgroups of MBC based on HER2 or triple negative status. Table III summarizes the data for subgroups of MBC for nab-paclitaxel; however, the same is not available for other NDDS formulations including PICN, Nanoxel and NPLS.

\section{Doxorubicin}

Current place in therapy. Doxorubicin is approved for the treatment of MBC and the most commonly used dose schedule is 60 to $75 \mathrm{mg} / \mathrm{m}^{2}$ as a single intravenous injection administered over 3 to 10 min every 3 weeks (57). Doxorubicin is recommended as a preferred single agent and as combination therapy with cyclophosphamide for the treatment of recurrent or MBC as per the NCCN guidelines. The toxicity profile of doxorubicin is of particular concern, which may hamper the required dosing and limit the use for rechallenge on relapse. Cardiotoxicity is generally seen at the high cumulative doses, and myelosuppression at individual doses. Other AEs that may limit doxorubicin treatment include alopecia, severe acute nausea and vomiting, and mucositis (15).

\section{Novel doxorubicin formulations}

Liposomal doxorubicin. Liposomal encapsulated formulation of doxorubicin was developed to address the cardiotoxicity concerns of the conventional formulation. Liposomal doxorubicin has been shown to be effective for the treatment of either anthracyclines-treated or naïve MBC patients as a single agent or in combination with other drugs $(5,58)$. A meta-analysis of 10 randomized controlled trials (RCTs) showed that liposomal doxorubicin offers significant advantages regarding the ORR [odds ratio $(\mathrm{OR})=1.25 ; 95 \% \mathrm{CI}, 1.02-1.52 ; \mathrm{P}=0.03$ ] and reduced cardiotoxicity $(\mathrm{OR}=0.46 ; 95 \% \mathrm{CI}, 0.23-0.92 ; \mathrm{P}=0.03)$ relative to conventional doxorubicin in advanced breast cancer patients (59). However, conventional liposomal formulations have limited clinical uses owing to a short circulation half-life as reticulo-endothelial system 3 (RES3) removes it from the circulation within a few minutes to a few hours, subsequent to the acquisition of opsonins from the plasma $(60,61)$.

Pegylated liposomal doxorubicin. Polyethylene glycol (PEG)-coated (pegylated; Stealth ${ }^{\circledR}$ ) liposomes are stable and long-circulating drug carriers. Pegylated-liposome encapsulated doxorubicin (PLD) contains the drug encapsulated in liposomes with surface-bound methoxypolyethylene glycol with a diameter of $<100 \mathrm{~nm}$, which exert an extremely long circulating half-life of 2-3 weeks after PLD injection, and has a reduced plasma clearance and volume of distribution compared with liposomal doxorubicin or free doxorubicin formulations (62). PLD extravasates through leaky tumor vasculature into the tissue compartments and doxorubicin penetrates into the tumor and exerts the chemotherapeutic effect. PLD is stable and remains intact in the circulation, and is responsible for the reduced toxicity without impacting efficacy $(63,64)$. The approved dose of PLD is $50 \mathrm{mg} / \mathrm{m}^{2} \mathrm{IV}$ infusion over $60 \mathrm{~min}$ every 4 weeks for breast cancer. It should be administered at an initial rate of $1 \mathrm{mg} / \mathrm{min}$ to minimize the risk of infusion reactions, and the rate can be increased to complete the administration over $1 \mathrm{~h}$ (65). PLD is recommended as the preferred single agent for the treatment of recurrent or MBC as per NCCN guidelines.

The most common dose of PLD in clinical practice is $40-50 \mathrm{mg} / \mathrm{m}^{2} ; 30 \mathrm{mg} / \mathrm{m}^{2}$ dose is very rarely used according to the panel members $(100 \%)$ (Table I).

PLD vs. conventional doxorubicin. All the expert panel members (100\%) agreed that they prefer PLD over conventional doxorubicin in recurrent or MBC. The expert panel members $(100 \%)$ also opined that PLD has a definite place in the management of MBC but its role in adjuvant and neoadjuvant settings is not proven and requires additional data. According to the expert panel, PLD can also be considered in 'special settings' including patients with anthracycline rechallenge and reduced cardiac tolerability (Table I).

PLD has demonstrated a favorable toxicity profile with better cardiac safety and less myelosuppression, alopecia, nausea and vomiting compared with the conventional anthracyclines in a meta-analysis of 10 RCTs conducted by Rafiyath et al (58). Furthermore, O'Brien et al demonstrated that PLD (50 mg/m² every 4 weeks) and conventional doxorubicin (60 mg/m $\mathrm{m}^{2}$ every 3 weeks) demonstrated comparable efficacy $(\mathrm{PFS}=6.9$ vs. 7.8 months, respectively; $\mathrm{HR}=1.00$; 95\% CI, 0.82-1.22), whereas risk of cardiotoxicity was significantly higher with conventional doxorubicin as compared with PLD (HR=3.16; 95\% CI, 1.58-6.31; $\mathrm{P}<0.001)$ in the first-line treatment of women $(n=509)$ with $\mathrm{MBC}$ who had normal cardiac functions. Also, the PLD arm had a lower incidence of myelosuppression, nausea, vomiting and alopecia compared with conventional doxorubicin (15). Majority (77\%) of the expert panel members opined that PLD is less cardiotoxic than conventional doxorubicin; however, benefits of PLD are not clear in terms of other toxicities. The expert panel members $(100 \%)$ opined that they were not sure if PLD is more effective than conventional doxorubicin in MBC (Table I). 
Table III. Use of NDDS formulations in different subgroups of MBC.

\begin{tabular}{|c|c|c|c|c|c|}
\hline Study & NDDS formulation & Subgroup of MBC & Dosing regimen & Efficacy outcomes & (Refs.) \\
\hline $\begin{array}{l}\text { Danso et al, } \\
2008\end{array}$ & Nab-paclitaxel & HER2 negative & $\begin{array}{l}\text { Weekly nab-paclitaxel } \\
\left(125 \mathrm{mg} / \mathrm{m}^{2}\right)+2 \text {-weekly } \\
\text { bevacizumab }(10 \mathrm{mg} / \mathrm{kg}) \\
\text { in } 4 \text { weekly cycle }\end{array}$ & PFS: 9.4 months & $(50)$ \\
\hline $\begin{array}{l}\text { Conlin et al, } \\
2010\end{array}$ & Nab-paclitaxel & HER2 positive & $\begin{array}{l}\text { Weekly nab-paclitaxel } \\
100 \mathrm{mg} / \mathrm{m}^{2}+\text { carboplatin } \\
\text { AUC }=2+\text { trastuzumab } \\
(4 \mathrm{mg} / \mathrm{kg} \text { followed by } \\
2 \mathrm{mg} / \mathrm{kg}) \text { in } 4 \text {-weekly cycle }\end{array}$ & PFS: 16.6 months & (51) \\
\hline $\begin{array}{l}\text { Mirtsching et al, } \\
2011\end{array}$ & Nab-paclitaxel & $\begin{array}{l}\text { HER2 negative and } \\
\text { HER2 positive }\end{array}$ & $\begin{array}{l}\text { Weekly nab-paclitaxel } \\
\left(125 \mathrm{mg} / \mathrm{m}^{2}\right) \text { and } \\
\text { trastuzumab }(4 \mathrm{mg} / \mathrm{kg} \\
\text { followed by } 2 \mathrm{mg} / \mathrm{kg} \text { weekly) }\end{array}$ & $\begin{array}{l}\text { HER2 negative PFS: } \\
12.8 \text { months HER2 } \\
\text { positive PFS: } \\
18.7 \text { months }\end{array}$ & $(52)$ \\
\hline $\begin{array}{l}\text { Hamilton et al, } \\
2013\end{array}$ & Nab-paclitaxel & mTNBC & $\begin{array}{l}\text { Weekly nab-paclitaxel } \\
\left(100 \mathrm{mg} / \mathrm{m}^{2}\right)+\text { carboplatin } \\
(\mathrm{AUC}=2)+2 \text {-weekly } \\
\text { bevacizumab }(10 \mathrm{mg} / \mathrm{kg}) \\
\text { in } 4 \text { weekly cycle }\end{array}$ & PFS: 9.2 months & (53) \\
\hline Chia et al, 2006 & PLD & HER2 positive & $\begin{array}{l}\text { PLD }\left(50 \mathrm{mg} / \mathrm{m}^{2} \text { every }\right. \\
4 \text { weeks })+ \text { weekly } \\
\text { trastuzumab }(4 \mathrm{mg} / \mathrm{kg} \\
\text { followed by } 2 \mathrm{mg} / \mathrm{kg})\end{array}$ & PFS: 12.0 months & (69) \\
\hline $\begin{array}{l}\text { Martín et al, } \\
2011\end{array}$ & PLD & HER2 positive & $\begin{array}{l}\text { PLD } 50 \mathrm{mg} / \mathrm{m}^{2} \text { and } \\
\text { cyclophosphamide } \\
600 \mathrm{mg} / \mathrm{m}^{2} \text { every } 4 \text { weekly } \\
\text { plus weekly trastuzumab } \\
(4 \mathrm{mg} / \mathrm{kg} \text { followed by } 2 \mathrm{mg} / \mathrm{kg} \text { ) }\end{array}$ & TTP: 12 months & (70) \\
\hline
\end{tabular}

AUC, area under the curve; HER2, human epidermal growth factor receptor 2; MBC, metastatic breast cancer; mTNBC, metastatic triple negative breast cancer; NDDS, novel drug delivery system; PLD, pegylated liposomal doxorubicin; TTP, time to disease progression.

Cumulative dose of PLD. All the panel members (100\%) were of the opinion that there is no ceiling dose level established for PLD, and also they were not sure if there should be any limit on the cumulative dose of PLD (Table I).

Toxicity profile of PLD: Palmar-plantar erythrodysesthesia. Palmar-plantar erythrodysesthesia (PPE, also called as hand-foot syndrome), manifested by a painful erythematous rash, often associated with edema, located on the palms, fingers and soles, is a dose limiting adverse effect associated with doxorubicin. The incidence of PPE was higher with PLD as compared to conventional doxorubicin with $\sim 50 \%$ of all patients receiving PLD having PPE (grade 3 PPE: $20 \%$ ) at the currently approved dose of $50 \mathrm{mg} / \mathrm{m}^{2}$ every 4 weeks $(15,66)$. However, a meta-analysis of 9 RCTs revealed that the conventional anthracyclines did not show statistically significant advantage over liposomal preparations (PLD or liposomal doxorubicin) in PPE events (OR, 1.08; 95\% CI, 0.11-10.30) (58). Majority (73\%) of the expert panel members opined that PPE is more common with PLD than with conventional doxorubicin. The expert panel members $(100 \%)$ felt that PPE is a manageable event, and that myelotoxicity, neutropenia, hypersensitivity and infusion site reactions are the other toxicities of concern with PLD treatment (Table I).

PLD in anthracycline rechallenge. A pooled analysis using individual data from four prospective trials of PLD involving 935 patients (274 had prior exposure to conventional anthracyclines and received PLD in a metastatic setting), demonstrated that anthracycline rechallenge using PLD was effective in patients who have a favorable performance status, regardless of setting, resistance, cumulative dose or time since prior conventional anthracycline therapy (67). According to $67 \%$ of the panel members, it is safe to rechallenge patients with PLD in MBC setting, who are exposed earlier to doxorubicin in an adjuvant setting. However, all the panel members opined that the need to rechallenge MBC patients with PLD rarely arises due to the availability of several other treatment options (Table I).

$P L D$ in the elderly with $M B C$. As a first-line treatment, PLD ( $45 \mathrm{mg} / \mathrm{m}^{2}$ every 4 weeks) was shown to be effective in elderly ( $\geq 65$ years) patients with MBC in a multicentric, phase III trial (68). In the elderly or patients with borderline cardiac 
function, all the expert panel members (100\%) would prefer to use PLD over conventional doxorubicin (Table I).

Combination of PLD with trastuzumab. Preclinical studies have suggested a synergistic effect of the combination of PLD and trastuzumab. A multicenter, phase II study demonstrated that PLD $\left(50 \mathrm{mg} / \mathrm{m}^{2}\right.$ every 4 weeks for six cycles $)$ in combination with weekly trastuzumab $(4 \mathrm{mg} / \mathrm{kg}$ loading dose and $2 \mathrm{mg} / \mathrm{kg}$ thereafter) was well-tolerated and active as the first-line therapy in women $(n=30)$ with HER2-positive MBC. There was an observed cardiotoxicity rate with this combination; however, it was expected to be lower than rates with conventional doxorubicin plus trastuzumab (69). The GEICAM study showed that the combination of PLD $50 \mathrm{mg} / \mathrm{m}^{2}$ and cyclophosphamide $600 \mathrm{mg} / \mathrm{m}^{2}$ administered every 4 weeks for six cycles, and trastuzumab (4 mg/kg loading dose, and $2 \mathrm{mg} / \mathrm{kg}$ thereafter) was safe and effective as a first-line treatment for women with HER2-overexpressing MBC at 24 weeks (70). Though there is data available, most $(77 \%)$ of the panel members opined that trastuzumab cannot be used concurrently with PLD (Table I).

Generic PLD formulations. Several generic PLD formulations including Lipodox ${ }^{\circledR}$, Pegadria $^{\circledR}$, Nudoxa $^{\circledR}$ (non-pegylated) are available in the Indian market. Pegadria has shown bioequivalence with the marketed product Doxil ${ }^{\circledR}$ in patients with ovarian cancer, and has demonstrated similarity in physico-chemical properties, and safety (71). However, there is no data available on the clinical efficacy of generic PLD in MBC. All the expert panel members were not sure if the available data on generic PLD formulations was satisfactory, and they did not have any preference among generic formulations. Furthermore, the expert panel felt that there was a need for more awareness regarding the process of regulatory approval for generic drugs (Table I).

The efficacy of doxorubicin formulations, alone or in combination with other agents, has been demonstrated in the treatment of advanced breast cancer. The efficacy of PLD has been established for HER2 positive subgroups; however, limited data is available on the other subgroups of MBC for conventional doxorubicin, liposomal doxorubicin or PLD.

\section{Conclusions}

Conventional formulations of the most commonly used drugs for the treatment of MBC have issues with safety and efficacy because of the carriers used [for taxanes (docetaxel and paclitaxel)], or cardiotoxicity and narrow therapeutic index [for anthracyclines (doxorubicin)]. Several nanoparticle based NDDSs have been developed to fulfill the unmet need to overcome the limitations of conventional formulations.

NDDSs have been developed to overcome the toxicity of the vehicles (i.e., CrEL and polysorbate 80 ) used in conventional taxane formulations, with improved stability and pharmacokinetics. They have shown better therapeutic outcomes compared with the conventional formulations without the need for corticosteroid premedication. Overall, novel formulations appear promising in the treatment of advanced solid tumors and the expert panel members agreed that these formulations are useful in patients with metastatic disease and those at risk of hypersensitivity reactions, diabetes and patients in whom they want to avoid steroids.
In order to increase the therapeutic index, doxorubicin is formulated with pegylated liposomal-encapsulation technique (pegylated liposomal doxorubicin), which increases the efficacy and reduces the toxicity (cardiotoxicity, myelosuppression etc.) of doxorubicin by altering tissue distribution. Pegylated liposomal doxorubicin has shown good clinical outcomes in terms of safety and efficacy and the expert panel members agreed that it can be considered as an alternative for patients with $\mathrm{MBC}$ when conventional anthracycline is inappropriate.

Limited data is available on the effectiveness of conventional or NDDS formulations of docetaxel, paclitaxel and doxorubicin in the treatment of subgroups of patients with advanced breast cancer including ER/PR positive, HER2 positive and TNBC. Further clinical studies are warranted to establish the effectiveness of NDDS formulations in these subgroups.

\section{Expert panel recommendations}

There is a need to generate more data to prove that newer NDDS formulations exhibit a significant advantage in terms of efficacy and tolerability when compared to conventional formulations.

Despite the development, clinical efficacy and safety data of NDDS formulations, conventional formulations still enjoy preference, primarily because of cost constraints.

The newer NDDS formulations of taxanes should be considered in special circumstances such as diabetics, patients who have had hypersensitivity reactions to conventional preparations in the past and in cases where steroids need to be avoided.

Novel formulations of doxorubicin should be used in the elderly and patients with borderline cardiac function.

\section{Acknowledgements}

Mr. Shreekant Sharma (Lambda Therapeutic Research, Ltd.) provided writing assistance and Dr Venugopal Madhusudhana (Lambda Therapeutic Research, Ltd.) provided additional editorial assistance for the development of this manuscript.

\section{Funding}

The expert opinion meeting and the manuscript development was funded by Intas Pharmaceuticals, Ltd.

\section{Availability of data and materials}

Not applicable.

\section{Authors' contributions}

This article is based on presentations and discussions regarding NDDSs from the consensus group meeting held on 10 September 2016 at the Indian Cooperative Oncology Network conference in Mumbai, India. The meeting was followed up by several deliberations and iterations that included in-person discussions and email exchanges prior to finalizing the manuscript. The NDDS consensus group comprised the 
following members: Moderators: SR and AJ. Members: DDC, UB, RR, AD, GB, PB, TVST, SK, KK, MK, AT, PD and AG. NJ, JS, DB and MK (Intas Pharmaceuticals, Ltd.) contributed to the intellectual content for the discussion and along with all the other authors, helped in the development and scientific review of the manuscript.

\section{Ethics approval and consent to participate}

Not applicable.

\section{Patient consent for publication}

Not applicable.

\section{Competing interests}

NJ, DB, JS, and MK are employees of Intas Pharmaceuticals, Ltd.

\section{References}

1. World Health Organization: GLOBOCAN 2012: Estimated cancer incidence, Mortality and Prevalence Worldwide in 2012 v1.0.

2. National Cancer Registry Programme (India): Three-Year Report of Population Based Cancer Registries 2012-2014.

3. Nagrani R, Budukh A, Koyande S, Panse NS, Mhatre SS and Badwe R: Rural urban differences in breast cancer in India. Indian J Cancer 51: 277-281, 2014.

4. Agarwal G and Ramakant P: Breast cancer care in India: The current scenario and the challenges for the future. Breast Care (Basel) 3: 21-27, 2008.

5. Lao J, Madani J, Puértolas T, Alvarez M, Hernández A, Pazo-Cid R, Artal A and Antón Torres A: Liposomal doxorubicin in the treatment of breast cancer patients: A review. J Drug Deliv 2013: 456409, 2013.

6. Hortobagyi GN: Treatment of breast cancer. N Engl J Med 339: 974-984, 1998

7. Ellis MJ, Hayes DF, Lippman ME: Treatment of metastatic breast cancer. In: Disease of the breast. Harris JR, Lippman ME, Morrow M, et al: (eds) Lippincott Williams \& Wilkins, 4th ed. Philadelphia, pp749, 2000.

8. Henderson IC: Chemotherapy for metastatic disease. In: Breast disease. Harris JR, Hellman S, Henderson IC, et al: (eds) J.B. Lippincott Company, 2nd ed. Philadelphia, pp604-665, 1991.

9. Sánchez-Moreno P, Boulaiz H, Ortega-Vinuesa JL, Peula-García JM and Aránega A: Novel drug delivery system based on docetaxel-loaded nanocapsules as a therapeutic strategy against breast cancer cells. Int J Mol Sci 13: 4906-4919, 2012.

10. Norris LB, Qureshi ZP, Bookstaver PB, Raisch DW, Sartor O, Chen H, Chen Fei and Bennett CL: Polysorbate 80 hypersensitivity reactions: A renewed call to action. Commun Oncol 7: 425-428, 2010.

11. Fumoleau P, Chevallier B, Kerbrat P, Krakowski Y, Misset JL, Maugard-Louboutin C, Dieras V, Azli N, Bougon N, Riva A and Roche H: A multicentre phase II study of the efficacy and safety of docetaxel as first-line treatment of advanced breast cancer: Report of the Clinical Screening Group of the EORTC. Ann Oncol 7: 165-171, 1996.

12. ten Tije AJ, Verweij J, Loos WJ and Sparreboom A: Pharmacological effects of formulation vehicles: Implications for cancer chemotherapy. Clin Pharmacokinet 42: 665-685, 2003.

13. Gelderblom H, Verweij J, Nooter K and Sparreboom A: Cremophor EL: The drawbacks and advantages of vehicle selection for drug formulation. Eur J Cancer 37: 1590-1598, 2001.

14. de Jonge ME, Huitema AD, Schellens JH, Rodenhuis S and Beijnen JH: Population pharmacokinetics of orally administered paclitaxel formulated in Cremophor EL. Br J Clin Pharmacol 59: 325-334, 2005.

15. O'Brien ME, Wigler N, Inbar M, Rosso R, Grischke E, Santoro A, Catane R, Kieback DG, Tomczak P, Ackland SP, et al: Reduced cardiotoxicity and comparable efficacy in a phase III trial of pegylated liposomal doxorubicin $\mathrm{HCl}$ (CAELYX/Doxil) versus conventional doxorubicin for first-line treatment of metastatic breast cancer. Ann Oncol 15: 440-449, 2004
16. Tzakos AG, Briasoulis $\mathrm{E}$, Thalhammer $\mathrm{T}$, Jäger $\mathrm{W}$ and Apostolopoulos V: Novel oncology therapeutics: Targeted drug delivery for cancer. J Drug Deliv 2013: 918304, 2013.

17. Kushwaha SK, Rastogl A, Rai A and Singh S: Novel drug delivery system for anticancer drug: a review. Int J PharmTech Res 4: pp542-553, 2012.

18. Taxotere Prescribing Information: Sanofi-aventis U.S. LLC, NJ 08807. Revised May, 2015.

19. Harvey V, Mouridsen H, Semiglazov V, Jakobsen E, Voznyi E, Robinson BA, Groult V, Murawsky M and Cold S: Phase III trial comparing three doses of docetaxel for second-line treatment of advanced breast cancer. J Clin Oncol 24: 4963-4970, 2006.

20. National Comprehensive Cancer Network (NCCN): Breast Cancer Guidelines, 2017.

21. Mavroudis D, Papakotoulas P, Ardavanis A, Syrigos K, Kakolyris S, Ziras N, Kouroussis C, Malamos N, Polyzos A, Christophyllakis C, et al: Randomized phase III trial comparing docetaxel plus epirubicin versus docetaxel plus capecitabine as first-line treatment in women with advanced breast cancer. Ann Oncol 21: 48-54, 2010.

22. Marty M, Cognetti F, Maraninchi D, Snyder R, Mauriac L, Tubiana-Hulin M, Chan S, Grimes D, Antón A, Lluch A, et al: Randomized phase II trial of the efficacy and safety of trastuzumab combined with docetaxel in patients with human epidermal growth factor receptor 2-positive metastatic breast cancer administered as first-line treatment: The M77001 study group. J Clin Oncol 23: 4265-4274, 2005.

23. Esteva FJ, Valero V, Booser D, Guerra LT, Murray JL, Pusztai L, Cristofanilli M, Arun B, Esmaeli B, Fritsche HA, et al: Phase II study of weekly docetaxel and trastuzumab for patients with HER-2-overexpressing metastatic breast cancer. J Clin Oncol 20: 1800-1808, 2002.

24. Baselga J, Cortés J, Kim SB, Im SA, Hegg R, Im YH, Roman L, Pedrini JL, Pienkowski T, Knott A, et al: Pertuzumab plus trastuzumab plus docetaxel for metastatic breast cancer. N Engl J Med 366: 109-119, 2012.

25. Miles DW, Chan A, Dirix LY, Cortés J, Pivot X, Tomczak P, Delozier T, Sohn JH, Provencher L, Puglisi F, et al: Phase III study of bevacizumab plus docetaxel compared with placebo plus docetaxel for the first-line treatment of human epidermal growth factor receptor 2-negative metastatic breast cancer. J Clin Oncol 28: 3239-3247, 2010.

26. Glück S, Russell C, O'Shaughnessy J, McKenna EF, Hu S, Odom D and Blum JL: Treatment effect of capecitabine and docetaxel or docetaxel alone by oestrogen receptor status in patients with metastatic breast cancer: Results of an exploratory analysis. Breast 22: 1087-1093, 2013.

27. Fan Y, Xu BH, Yuan P, et al: Docetaxel-cisplatin might be superior to docetaxel-capecitabine in the first-line treatment of metastatic triple-negative breast cancer. Ann Oncol 24: 1219-1225, 2013.

28. Ashraf M, Sajjad R, Khan M, Shah M, Bhat Y and Wani Z: 156P-Efficacy and safety of a novel nanosomal docetaxel lipid suspension (NDLS) as an anti cancer agent-a retrospective study. Ann Oncol 27 (Suppl 9): ix46-ix51, 2016.

29. Rivera E, Mejia JA, Arun BK, Adinin RB, Walters RS, Brewster A, Broglio KR, Yin G, Esmaeli B, Hortobagyi GN and Valero V: Phase 3 study comparing the use of docetaxel on an every-3-week versus weekly schedule in the treatment of metastatic breast cancer. Cancer 112: 1455-1461, 2008.

30. Nuzzo F, Morabito A, Gravina A, Di Rella F, Landi G, Pacilio C, Labonia V, Rossi E, De Maio E, Piccirillo MC, et al: Effects on quality of life of weekly docetaxel-based chemotherapy in patients with locally advanced or metastatic breast cancer: Results of a single-centre randomized phase 3 trial. BMC Cancer 11: 75, 2011.

31. Seidman AD, Berry D, Cirrincione C, Harris L, Muss H, Marcom PK, Gipson G, Burstein H, Lake D, Shapiro CL, et al: Randomized phase III trial of weekly compared with every-3-weeks paclitaxel for metastatic breast cancer, with trastuzumab for all HER-2 overexpressors and random assignment to trastuzumab or not in HER-2 nonoverexpressors: Final results of Cancer and Leukemia Group B protocol 9840. J Clin Oncol 26: 1642-1649, 2008.

32. Wist EA, Mjaaland I, Løkkevik E and Sommer H: Weekly paclitaxel plus capecitabine versus docetaxel every 3 weeks plus capecitabine in metastatic breast cancer. J Oncol 2012: 862921, 2012. 
33. Zhang $\mathrm{L}$ and Zhang N: How nanotechnology can enhance docetaxel therapy. Int J Nanomedicine 8: 2927-2941, 2013.

34. Ahmad A, Sheikh S, Ali SM, Ahmad MU, Paithankar M, Saptarishi D, Maheshwari K, Kumar K, Singh J, Patel GN, et al: Development of aqueous based formulation of docetaxel: Safety and pharmacokinetics in patients with advanced solid tumors. J Nanomed Nanotechnol 6: 295, 2015.

35. Ahmad A, Sheikh S, Taran R, Srivastav SP, Prasad K, Rajappa SJ, Kumar V, Gopichand M, Paithankar M, Sharma M, et al: Therapeutic efficacy of a novel nanosomal docetaxel lipid suspension compared with taxotere in locally advanced or metastatic breast cancer patients. Clin Breast Cancer 14: 177-181, 2014.

36. Seidman AD, Tiersten A, Hudis C, Gollub M, Barrett S, Yao TJ Lepore J, Gilewski T, Currie V, Crown J, et al: Phase II trial of paclitaxel by 3 -hour infusion as initial and salvage chemotherapy for metastatic breast cancer. J Clin Oncol 13: 2575-2581, 1995.

37. Taxol Prescribing Information: Bristol-Myers Squibb Company Princeton, NJ 08543. Revised April, 2011

38. Perez EA, Vogel CL, Irwin DH, Kirshner JJ and Patel R: Multicenter phase II trial of weekly paclitaxel in women with metastatic breast cancer. J Clin Oncol 19: 4216-4223, 2001.

39. Slamon DJ, Leyland-Jones B, Shak S, Fuchs H, Paton V, Bajamonde A, Fleming T, Eiermann W, Wolter J, Pegram M, et al: Use of chemotherapy plus a monoclonal antibody against HER2 for metastatic breast cancer that overexpresses HER2. N Engl J Med 344: 783-792, 2001

40. Datko F, D'Andrea G, Dickler M, Theodoulou M, Goldfarb S, Lake D, Fornier M, Modi S, Sklarin N, Comen E, et al: Abstract P5-18-20: Phase II study of pertuzumab, trastuzumab, and weekly paclitaxel in patients with metastatic HER2-overexpressing metastatic breast cancer. Cancer Res 72 (24 Suppl): Abstract nr P5-18-20, 2012.

41. Delaloge S, Pérol D, Courtinard C, Brain E, Asselain B, Bachelot T, Debled M, Dieras V, Campone M, Levy C, et al: Paclitaxel plus bevacizumab or paclitaxel as first-line treatment for HER2-negative metastatic breast cancer in a multicenter national observational study. Ann Oncol 27: 1725-1732, 2016.

42. Hu XC,Zhang J, Xu BH, Cai L, RagazJ, Wang ZH, Wang BY, Teng YE Tong ZS, Pan YY, et al: Cisplatin plus gemcitabine versus paclitaxe plus gemcitabine as first-line therapy for metastatic triple-negative breast cancer (CBCSG006): A randomised, open-label, multicentre, phase 3 trial. Lancet Oncol 16: 436-446, 2015.

43. Saloustros E, Nikolaou M, Kalbakis K, Polyzos A, Christofillakis C, Kentepozidis N, Pistamaltzian N, Kourousis C, Vamvakas L, Georgoulias V and Mavroudis D: Weekly paclitaxel and carboplatin plus bevacizumab as first-line treatment of metastatic triple-negative breast cancer. A Multicenter Phase II Trial by the Hellenic Oncology Research Group. Clin Breast Cancer 18: 88-94, 2018.

44. Mauri D, Kamposioras K, Tsali L, Bristianou M, Valachis A Karathanasi I, Georgiou C and Polyzos NP: Overall survival benefit for weekly vs. three-weekly taxanes regimens in advanced breast cancer: A meta-analysis. Cancer Treat Rev 36: 69-74, 2010.

45. Trissel LA: Pharmaceutical properties of paclitaxel and their effects on preparation and administration. Pharmacotherapy 17 133S-139S, 1997

46. Abraxane Prescribing Information: Abraxis BioScience, LLC. Revised September, 2013

47. Gradishar WJ, Tjulandin S, Davidson N, Shaw H, Desai N, Bhar P, Hawkins M and O'Shaughnessy J: Phase III trial of nanoparticle albumin-bound paclitaxel compared with polyethylated castor oil-based paclitaxel in women with breast cancer. J Clin Oncol 23: 7794-7803, 2005.

48. Gradishar WJ, Krasnojon D, Cheporov S, Makhson AN, Manikhas GM, Clawson A and Bhar P: Significantly longer progression-free survival with nab-paclitaxel compared with docetaxel as first-line therapy for metastatic breast cancer. J Clin Oncol 27: 3611-3619, 2009.

49. Blum JL, Savin MA, Edelman G, Pippen JE, Robert NJ, Geister BV, Kirby RL, Clawson A and O'Shaughnessy JA: Phase II study of weekly albumin-bound paclitaxel for patients with metastatic breast cancer heavily pretreated with taxanes. Clin Breast Cancer 7: 850-856, 2007.

50. Danso MA, Blum JL, Robert NJ, Krekow L, Rotche R, Smith DA, Richards P, Anderson T, Richards DA and O'Shaughnessy J: Phase II trial of weekly nab-paclitaxel in combination with bevacizumab as first-line treatment in metastatic breast cancer. J Clin Oncol 26 (15 Suppl): S1075, 2008.

51. Conlin AK, Seidman AD, Bach A, Lake D, Dickler M, D'Andrea G, TrainaT,Danso M,Brufsky AM,SalehM, et al: Phase II trial of weekly nanoparticle albumin-bound paclitaxel with carboplatin and trastuzumab as first-line therapy for women with HER2-overexpressing metastatic breast cancer. Clin Breast Cancer 10: 281-287, 2010.
52. Mirtsching B, Cosgriff T, Harker G, Keaton M, Chidiac T and Min M: A phase II study of weekly nanoparticle albumin-bound paclitaxel with or without trastuzumab in metastatic breast cancer. Clin Breast Cancer 11: 121-128, 2011.

53. Hamilton E, Kimmick G, Hopkins J, Marcom PK, Rocha G, Welch R, Broadwater G and Blackwell K: Nab-paclitaxel/bevacizumab/carboplatin chemotherapy in first-line triple negative metastatic breast cancer. Clin Breast Cancer 13: 416-420, 2013.

54. Jain MM, Gupte SU, Patil SG, P et al: Paclitaxel injection concentrate for nanodispersion versus nab-paclitaxel in women with metastatic breast cancer: A multicenter, randomized, comparative phase II/III study. Breast Cancer Res Treat 156: 125-134, 2016.

55. Ranade AA, Bapsy PP, Nag S, Raghunadharao D, Raina V, Advani SH, Patil S, Maru A, Gangadharan VP, Goswami C, et al: A multicenter phase II randomized study of Cremophor-free polymeric nanoparticle formulation of paclitaxel in women with locally advanced and/or metastatic breast cancer after failure of anthracycline. Asia Pac J Clin Oncol 9: 176-181, 2013.

56. Ahmad A, Sheikh S, Ali SM, Paithankar M, Mehta A, Nagarkar R, Krishnan S, Majumdar A, Mukherjee KK, Singh JK, et al: Nanosomal paclitaxel lipid suspension demonstrates higher response rates compared to paclitaxel in patients with metastatic breast cancer. J Cancer Sci Ther 7: 116-120, 2015.

57. Doxorubicin Prescribing Informaiton: Pharmacia \& Upjohn Company, Kalamazoo, MI 49001. Revised May, 2003.

58. Rafiyath SM,Rasul M,Lee B, Wei G,Lamba G and Liu D: Comparison of safety and toxicity of liposomal doxorubicin vs. conventional anthracyclines: A meta-analysis. Exp Hematol Oncol 1: 10, 2012.

59. Xing M, Yan F, Yu S and Shen P: Efficacy and cardiotoxicity of liposomal doxorubicin-based chemotherapy in advanced breast cancer: a meta-analysis of ten randomized controlled trials. PloS one 10: e0133569, 2015.

60. Cowens JW, Creaven PJ, Greco WR, Brenner DE, Tung Y, Ostro M, Pilkiewicz F, Ginsberg R and Petrelli N: Initial clinical (phase I) trial of TLC D-99 (doxorubicin encapsulated in liposomes). Cancer Res 53: 2796-2802, 1993.

61. Hong RL, Huang CJ,Tseng YL,Pang VF, Chen ST,Liu JJ and ChangFH: Direct comparison of liposomal doxorubicin with or without polyethylene glycol coating in C-26 tumor-bearing mice: Is surface coating with polyethylene glycol beneficial? Clin Cancer Res 5: 3645-3652, 1999.

62. Gabizon A and Martin F: Polyethylene glycol-coated (pegylated) liposomal doxorubicin. Rationale for use in solid tumours. Drugs 54 (Suppl 4): S15-S21, 1997.

63. Gabizon AA: Pegylated liposomal doxorubicin: Metamorphosis of an old drug into a new form of chemotherapy. Cancer Invest 19: 424-436, 2001.

64. Simůnek T, Stérba M, Popelová O, Adamcová M, Hrdina R and Gersl V: Anthracycline-induced cardiotoxicity: overview of studies examining the roles of oxidative stress and free cellular iron. Pharmacol Rep 61: 154-171, 2009.

65. Caely ${ }^{\circledR}$ summary of product characteristics. Janssen-Cilag International NV, Beerse, Belgium. Revised January, 2017.

66. Gordon AN, Fleagle JT, Guthrie D, Parkin DE, Gore ME and Lacave AJ: Recurrent epithelial ovarian carcinoma: A randomized phase III study of pegylated liposomal doxorubicin versus topotecan. J Clin Oncol 19: 3312-3322, 2001.

67. Al-Batran SE, Güntner M, Pauligk C, et al: Anthracycline rechallenge using pegylated liposomal doxorubicin in patients with metastatic breast cancer: A pooled analysis using individual data from four prospective trials. Br J Cancer 103: 1518-1523, 2010.

68. Smorenburg CH,De Groot SM, van Leeuwen-Stok AE, et al: A randomized phase III study comparing pegylated liposomal doxorubicin with capecitabine as first-line chemotherapy in elderly patients with metastatic breast cancer: Results of the OMEGA study of the Dutch Breast Cancer Research Group BOOG. Ann Oncol 25: 599-605, 2014.

69. Chia S, Clemons M, Martin LA, Rodgers A, Gelmon K, Pond GR and Panasci L: Pegylated liposomal doxorubicin and trastuzumab in HER-2 overexpressing metastatic breast cancer: A multicenter phase II trial. J Clin Oncol 24: 2773-2778, 2006.

70. Martín M, Sánchez-Rovira P, Muñoz M, , et al: Pegylated liposomal doxorubicin in combination with cyclophosphamide and trastuzumab in HER2-positive metastatic breast cancer patients: Efficacy and cardiac safety from the GEICAM/2004-05 study. Ann Oncol 22: 2591-2596, 2011.

71. Ali SM, Sheikh S, Ahmad A, Ahmad MU, et al: Bioequivalence study of pegylated doxorubicin hydrochloride liposome (PEGADRIA) and DOXIL ${ }^{\circledR}$ in ovarian cancer patients: Physicochemical characterization and pre-clinical studies. J Nanomed Nanotechnol 7: 361, 2016.

This work is licensed under a Creative Commons Attribution 4.0 International (CC BY 4.0) License. 